\title{
06 | Buscando luz en la tierra: bajo las bóvedas del Baño Real del Palacio de Comares_Miguel Guitart
}

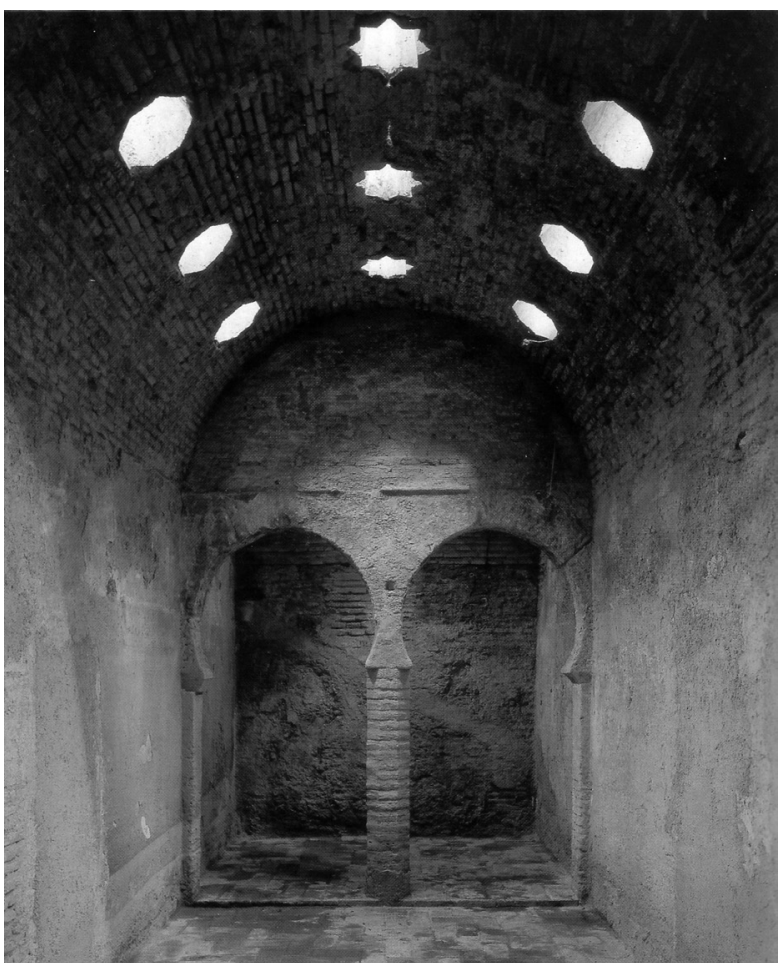

[1]

\section{Buscando luz en la tierra: Bajo las bóvedas del Baño Real del Palacio de Comares}

"De cómo se bañaban los árabes: de día, bajo estrellas de sol; de noche, bajo estrellas de luna"1.

Sería posible plantear la evolución de la cueva como un germen de las primeras aberturas en la masa arquitectónica. Este proceso, en el que se van produciendo cavidades que se asoman al exterior e introducen la luz natural en el interior, nos conduce a la determinación del hombre por salir de debajo de la tierra y dominar su entorno por medio de las primeras obras arquitrabadas. Podemos estimar que una construción que tiene a la tierra como medio de desarrollo queda unida a ella porque de ella surge, desde ella crece y en ella se sustenta, mientras que las construcciones que podríamos considerar desarrolladas en el aire serían aquellas que en su proceso evolutivo o en su formación constructiva quedan desligadas de la tierra y parecen flotar y desenvolverse sin servidumbres de peso. Las primeras se podrían relacionar con la cueva estereotómica mientras que las segundas lo harían con el bosque tectónico. La tierra que se perfora y se abre al exterior puede ser planteada como un claro antecedente en el origen de los planos estereotómicamente perforados. Para ilustrar este primer espacio donde la intervención de la mano del hombre abre unos huecos que le acercan a la luz, podríamos valernos de las tumbas laberínticas en los enterramientos en el Egipto del Imperio Antiguo, del Panteón de Agrippa o de la Villa de Adriano, ambas en Roma y del siglo I a.C. y II d.C. respectivamente, o de los hammams islámicos posteriores. Todos ellos muestran la condición inequívoca de la caverna al abrir la bóveda del espacio. La cueva supone por tanto un modelo inconfundible que es explorado por autores clásicos y contemporáneos para ser retomado con posterioridad por arquitectos del Movimiento Moderno como el propio Le Corbusier quien, impactado por la Villa de Adriano en Tívoli en su viaje de 1910, aplicó soluciones inspiradas en la obra romana en uno de sus más sobresalientes espacios, la iglesia de Nôtre Dame du Haut en Ronchamp, de $1956^{2}$.

\section{El Baño Real del Palacio de Comares. La Alhambra, Granada}

"Cuando se alza la mirada al cielo, se lo ve negro, sembrado de vagos resplandores; solo poco a poco las estrellas se fijan y disponen en dibujos precisos, y cuanto más se mira, más se ven aparecer"3.
Resumen pág 55 | Bibliografía pág 60

Miguel Guitart es Doctor Arquitecto por la Escuela Técnica Superior de Arquitectura de la Universidad Politécnica de Madrid con calificación de Sobresaliente Cum Laude y Visiting Associate Professor en la School of Architecture and Planning de la University at Buffalo, State University of New York. En 2003 obtiene su título de Master in Architecture en el Graduate School of Design de la Universidad de Harvard como becario J. W. Fulbright. Durante esos años imparte clase como Visiting Critic en el Boston Architectural College BAC y participa en el programa de arquitectura Career Discovery del GSD de Harvard. Entre 2006 y 2014 es Profesor Asociado de Proyectos en la Escuela de Arquitectura de la Universidad Pontificia de Salamanca en Madrid UPSAM y, entre 2013 y 2014, es también Profesor Asociado en la Escuela de Ingeniería y Arquitectura de la Universidad de Zaragoza EINE UNIZAR. En 2009 forma el equipo profesional Gimeno Guitart con Daniel Gimeno. Su trabajo ha sido ampliamente seleccionado y premiado por el Colegio de Arquitectos de Sevilla COAS, los Premios de Arquitectura y Urbanismo de Mallorca o el programa Arquia Próxima de la Caja de Arquitectos, así como expuesto en Madrid, Palma de Mallorca, Sevilla, Nueva York, Bruselas, Venecia, Estocolmo, París, Roma, Houston, Dallas, Montreal, Toronto y Oporto. Profesor invitado en Boston, Buffalo, Washington, Madrid y Sevilla, es autor de numerosos artículos y editor ocasional, entre otros, de la serie Práctica Arquitectónica.

\section{Palabras clave}

Arquitectura de tierra, arquitectura Islámica, Alhambra, estrategias de perforación, arquitecturas excavadas, luz subterránea 
1 "Se diría que las estrellas han traspasado la bóveda y se deslizan por el pavimento. Estrellas en forma de gotas, de cuadrados y de círculos. Moldes de galletas de luz. Hoy son cristales transparentes. Quizás una vez fueran de colores". TORRES TUR, Elías, Luz cenital, tesis doctoral, Barcelona: COAC, 2004, p. 44.

2 El hombre desea dominar también el aire y su arquitectura tratará, de forma casi sistemática, de evadir la obligada gravedad, logrando retos si acaso de mayor dificultad que cuando se alia con la tierra como honesto soporte de su estructura. La capacidad de las construcciones de expresar el origen que las concibe puede referirlas a la tierra y ser pesadas, lentas, inmóviles y oscuras, o bien referirlas al aire y ser ligeras, ágiles, dinámicas, luminosas. Una lectura en profundidad tal vez nos llevaría a agrupar las primeras por su carácter estático y arcaico, involucradas en el tiempo de la memoria, mientras que las segundas se verían como dinámicas e implicadas con lo liviandad más contemporánea.

3 CALVINO, Italo, Palomar (1983), Madrid: Editorial Siruela, 1990, p. 48. Traducción de Aurora Bernárdez.

${ }^{4}$ La palabra paraiso, que hoy significa "cielo"o

A lo largo de la cultura islámica se han producido soluciones espaciales de enorme riqueza arquitectónica y refinamiento estético. El baño o hammam es con probabilidad uno de los más singulares. Procedente de las pautas establecidas por los praefurnium de las termas romanas, estos ejes se convirtieron en salas fundamentales de la vida social del mundo islámico. Cabría destacar en España ejemplos tan relevantes como los Baños de Alí en Jaén del siglo X, el Bañuelo del Albaicín en Granada del siglo XI, o el más representativo de todos ellos, el Baño de Comares en el palacio-fortaleza de la Alhambra del siglo XIV. Todos ellos se caracterizan por sus bóvedas perforadas de ladrillo a modo de grandes moldes de luz que, si bien cumplían una misión funcional como la de introducir luz natural y regular la temperatura y la cantidad de vapor de agua en el interior, también transformaban por completo el espacio por medio de la luz y las sombras, haciendo de estas salas lugares muy característicos de su propia cultura. [1]

El hammam del Baño del Palacio de Comares, también conocido como Baño Real por haber sido de uso particular de los Reyes Católicos, se remonta a la época de Yusuf I (1333-1354). El Baño Real o de Comares constituye uno de los espacios de mayor interés dentro del conjunto de la Alhambra, con uno de los hammam en mejor estado de conservación hasta la fecha en Occidente, prácticamente íntegro a pesar de algunas modificaciones estructurales y un mantenimiento más testimonial que funcional. El Baño de Comares ha sido para visitantes, intelectuales y artistas uno de los lugares de mayor fascinación de todo el conjunto palaciego de la Alhambra. Desde el viajero y cronista Hieronymus Münzer, en 1494, hasta el vanguardista Henri Matisse, en 1910, muchos autores han quedado cautivados por la atmósfera de misterio de su luz filtrada. Otras muestras de ello son las planchas de Alexandre Laborde, de 1812, los planos levantados por Owen Jones o James Cavanah Murphy, en 1813, con detalles como el circuito de canalizaciones o la caldera del baño, o los apuntes de Richard Ford, de 1831. [2]

Ubicado entre los patios de los Arrayanes y de los Leones, junto a la sala de las Dos Hermanas, el Baño Real queda cerca de las dependencias del palacio de Comares con un acceso directo al patio de los Arrayanes. Un primer vestíbulo acoge el área para desnudarse y albergar la vestimenta antes de entrar en las zonas húmedas. Desde esta primera sala se desciende a la sala de reposo o bayt al-maslaj, también conocida como sala de las Camas debido a dos amplios aposentos ligeramente elevados que flanquean el espacio principal. Las puertas que flanquean las camas forman parte de la estructura original del baño, de las que, además de la de acceso, unas abren a almacenes de servicio y otras conducen a unas letrinas ubicadas tras las alcobas así como a las cámaras de vapor. [3]

El espacio principal se continúa con una zona de paso de reducidas dimensiones, llamado bayt al-barid, que contiene una pila de agua fría, a la que sucede la zona central del baño o bayt alwastani, la estancia más amplia y caldeada. Esta sala se divide en tres crujías siendo la central la de mayor anchura y las dos extremas menores en dimensión, flanqueadas por sendas arquerías de triple arco de herradura ligeramente apuntado. La bóveda central apoya sobre bóvedas menores en los laterales, salvando la mayor luz por medio de dos columnas a cada lado que dividen el espacio central de los extremos, resaltando de este modo un cuadrado perfecto en la planta. Este espacio queda ventilado e iluminado cenitalmente por las bóvedas perforadas con formas lobulares y estrelladas más reconocibles. Frente al vano de acceso a esta estancia, otro hueco conduce a la última sala caldeada del baño conocida como bayt al-sajun, a cuyos extremos y bajo amplios iwanes, dos grandes pilas vertían agua fría y caliente. Bajo el suelo de esta sala final se sitúa el hipocausto, junto al horno o al-furn y, tras un arco cegado al fondo, el horno. Próximo a esta zona se dispuso un espacio para almacenar el material combustible con una

[3]

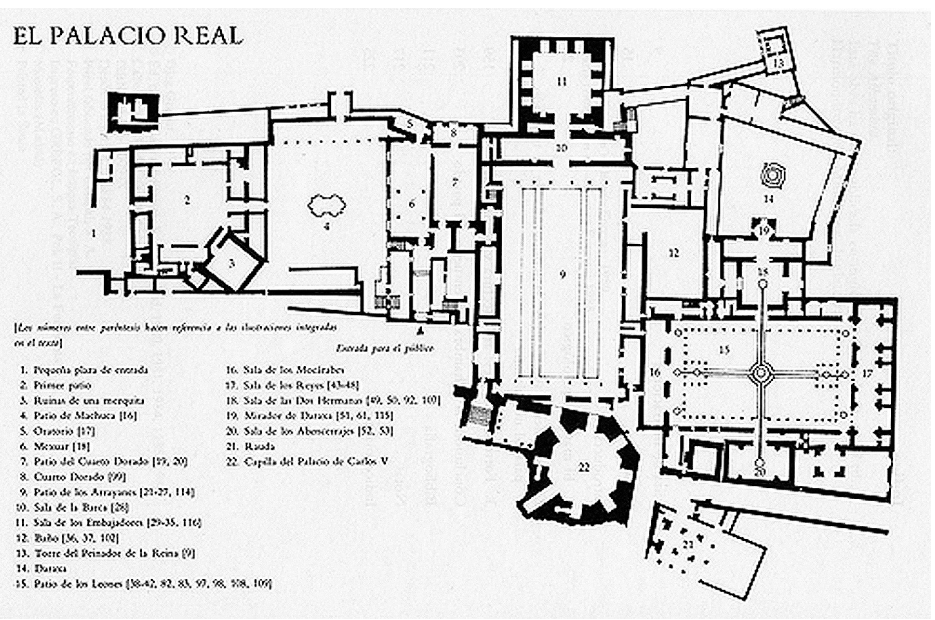


puerta secundaria de servicio. La sección realizada por Owen Jones en el siglo XIX nos presenta con claridad la secuencia de espacios que conduce a la sala del hammam por medio de una transición en penumbra desde el jardín de Lindaraja, del cual queda muy pronto desvinculado, hasta el espacio interior iluminado de forma vibrante. [4]

Las salas de vapor tienen solerías de mármol bajo las que discurren los conductos que distribuyen el vapor de agua, por lo que en estas salas se debía usar calzado de suela gruesa. Los muros de estas mismas estancias contienen las canalizaciones de barro de diferentes tamaños y secciones que conducían el aire caliente y el vapor del sistema con el fin de alcanzar la temperatura y la humedad necesarias para el baño. En el siglo XVI se renovaron algunos zócalos cerámicos de estas salas y se habilitó una nueva salida hacia el colindante patio de Lindaraja. Los elementos decorativos de las salas, tales como fuentes, pavimentos, columnas y azulejos son en gran parte originales. Los techos y las yeserías fueron reparados y repintados con colores intensos en la segunda mitad del siglo XIX.

La intencionada desconexión entre el patio de acceso y el recorrido interior de las dependencias del baño se acentúa tanto por la inmediata penumbra como por el tránsito quebrado y secuenciado entre unas estancias que pretenden alejar metafóricamente al hombre de su medio exterior. La intención es la de someter al visitante a una suerte de estadio extático donde la estrategia espacial se construye con una envolvente masiva penetrada cenitalmente por haces puntuales de luz en su momento álgido. El ritual del baño queda caracterizado por una suerte de viaje utópico al interior de la tierra, como a un oscuro y cálido vientre materno. [5]

El ámbito central del baño o bayt al-wastani presenta un típico ejemplo de cubierta realizada con bóveda de ladrillo y aperturas en formas alternas de lágrimas y estrellas cuya función era la de permitir la entrada de luz natural y la salida del exceso de vapor de agua. Dichas perforaciones en la masa ciega del aparejo son las que permiten una relación visualmente muy limitada, puramente lumínica, entre interior y exterior, permitiendo que la sala funcione como un recinto compacto y cerrado que se abre con prudencia mediante el filtro característicamente estereotómico de sus bóvedas. El mencionado plano en sección del espacio masivo y estático que de esta sala realiza Owen Jones en 1813 muestra una distinción entre la parte de la bóveda superior que se trabaja como un paramento, perforado y profundo, que fuerza una tensión vertical y enlaza visualmente con el cielo, y el tratamiento dado al zócalo por medio de un dibujo geométrico ciego y plano que enfatiza un falso horizonte en su remate superior de azulejo y vincula el espacio construido a la tierra. No hay transición entre ambos: de la recreación abstracta del jardín vegetal del zócalo se pasa a la bóveda celeste por medio de un paño intencionadamente aséptico carente de ornamento. Para desligar todavía más la horizontal de la tierra y la bóveda superior, esta última no nace como continuación de los testeros laterales sino que su apoyo sobre columnas avanza en sección y permite la formación de dos ámbitos laterales iluminados cenitalmente. Esta estrategia permite enfatizar la desvinculación conceptual de la bóveda oscura del nivel del zócalo perimetral. La visión del horizonte exterior queda en este caso excluida de cualquier protagonismo: como en otros baños de similares características, la visión del exterior queda anulada de forma intencionada en la experiencia del espacio interior. [6]

Es sabido que en los palacios de la Alhambra y en los jardines del Generalife se recreaba de forma recurrente la idea del Paraíso en la Tierra ${ }^{4}$. Dicha idea se construía por medio de experiencias sensoriales fabricadas por los juegos de reflexión en las láminas de agua ${ }^{5}$, la alteración sutil de los espacios por medio de cuidados efectos ópticos, el control específico de los llenos y vacíos de las masas construidas y los espacios abiertos, la aplicación decorativa en plementerías y mocárabes, donde sombras y dorados contribuían a dispersar visalmente los límites de las
[4] Planta del Baño Real. La Alhambra. Granada. Fuente: Patronato de La Alhambra y Generalife. Consejería de Cultura de Andalucía.

[5] Planta de techos del Baño Real. La Alhambra. Granada. Fuente: Patronato de La Alhambra y Generalife. Consejería de Cultura de Andalucia.
[4]

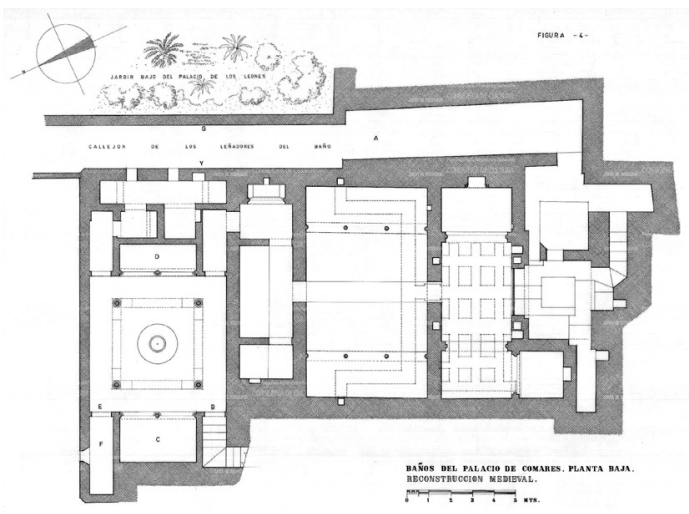

[5]

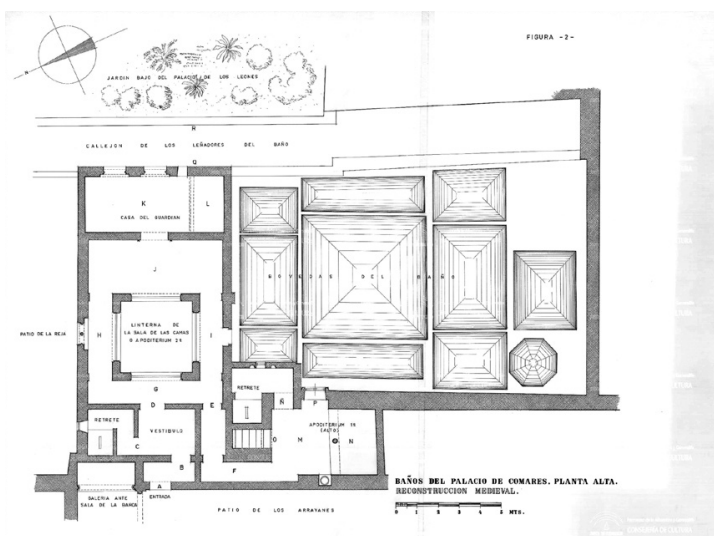


"algo inmensamente placentero", procede del persa pairidaeza o paerdís, "cercado", que es un compuesto de pairi-, "alrededor" (un cognado del griego peri-) y -diz, "crear",

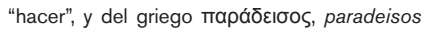
(en latín paradisus), usado para aludir al Jardin del Edén. Fuentes tan antiguas como Jenofonte en su Anábasis (siglo IV a. C.) aluden al famoso jardín "paraíso" persa. Así, su significado original hace referencia a un jardin extenso y bien arreglado, que se presenta como un lugar bello y agradable, donde además de árboles y flores se ven animales enjaulados o en libertad. El vínculo, por tanto, entre el jardín islámico y la noción de paraiso es algo muy directo.

5 Con el fin de que los hombres no alzaran la vista hacia las bóvedas y cúpulas se colocaron fuentes limpias como espejos donde poder descansar la mirada para poder contemplar el universo sin forzar el gesto ni ofender a Alá.

${ }^{6}$ Los geómetras árabes y persas eran figuras de enorme importancia en la construcción de estos espacios, siendo gran parte de ellos filósofos, matemáticos e incluso arquitectos a la vez. Véase BURCKHARDT, Titus, $L a$ Civilización Hispano-Árabe, Madrid: Alianza Editorial, Colección Alianza Universidad, 1977.

${ }^{7}$ Como ocurre en el Panteón de Roma. Véase ALGARÍN COMINO, Mario, Arquitecturas excavadas. El proyecto frente a la construcción del espacio, Colección Arquithesis $n^{\circ} 21$, Madrid: Fundación Caja de Arquitectos, 2006. 8 Son particularmente interesantes los textos de LAM, William M. C., "Lighting for Architecture", en Architectural Record, Nueva York, 1952. y LAM, William M. C., Perception and Lighting as Formgivers for Architecture, Editado por Christopher Hugh Ripman, Nueva York: McGraw-Hill,1977.

[6] Sección longitudinal del Baño Real. La Alhambra. Granada. Owen Jones. 1813. Fuente: Patronato de La Alhambray Generalife. Consejeria de Cultura de Andalucía.

[7] Detalle de techo del Baño Real. Estrellas tartésicas Rub El Hizb. Fotografia de autor desconocido. estancias, y sus omnipresentes y casi invisibles recorridos, así como el fuerte aroma de las flores y plantas en los arriates, todo ello bajo la aplicación de estrictas geometrías que ordenaban todos y cada uno de los elementos ${ }^{6}$. De modo similar, cuando observamos los espacios interiores del Baño Real y, en concreto, el característico espacio abovedado central cuajado de huecos, el concepto de Paraíso vuelve a ser retomado y se reproduce una vez más con nuevos mecanismos. El nuevo escenario de lo divino en la Tierra es, en esta ocasión, la noche estrellada sobre el mundo habitado por el hombre -experiencia muy ligada a la cultura del Islam en su histórica relación con los desiertos y amplias llanuras despobladas que eran recorridas por las primeras poblaciones nómadas-. Se produce en consecuencia un paralelismo entre la interpretación evocadora que ordena la secuencia de espacios exteriores e interiores. De esta forma, cuando los habitantes de los palacios de La Alhambra disfrutaban de sus sesiones de baño, la presencia visual del vapor, la elevada temperatura y las aromáticas infusiones que se servían permitían la experiencia eficaz de ser transportado a la contemplación de lo divino por medio de sus creaciones más perfectas como la noche cuajada de estrellas recreada en las bóvedas de ladrillo. [7]

Con objeto de potenciar aún más esta distinción entre la tierra de los hombres y la bóveda celeste como lugar superior que los ampara, se recurre a mecanismos muy específicos como el zócalo vítreo que circunda el espacio del hombre y lo delinea y ata al suelo con contundencia. El zócalo no sube más allá de la cota de los capiteles, lo que restringe su decoración al ámbito inmediato del hombre y libera una zona de nadie intermedia que funciona como transición visual y conceptual entre el mundo inferior del hombre y el mundo superior del paraíso. La segunda estrategia empleada consiste en una línea de imposta que delinea el seco final del zócalo de azulejo y que separa con claridad la bóveda perforada de los paramentos verticales. Esta línea horizontal y el distinto tratamiento ornamental que reciben las partes superior e inferior de los revestimientos de la sala, -geométrico y colorido abajo y plano, pobre, oscuro arriba- dividen el espacio vertical en dos ámbitos fácilmente distinguibles en una primera táctica tan directa como definitiva: el celestial y el terrenal. El suelo, habitualmente mojado y brillante, reflejaba los puntos de luz que se abrían en el cielo de la bóveda, generando una simetría con respecto a la horizontal que también tenía lugar en los jardines exteriores, donde las composiciones de ladrillo y vegetación se reflejaban en los estanques de aguas quietas. Esta simetría respecto del plano del suelo que multiplica por dos el número de las perforaciones en la sala principal del baño contribuye a distorsionar el espacio físico y material para reconfigurar un ámbito disperso de luces y sombras.

Como ocurre en otros filtros estereotómicos relacionados con la extracción del agujero en la masa, el espacio aparece cuando la entrada de luz corta el vacío oscuro del baño encerrado entre sus muros masivos de ladrillo ${ }^{7}$. Se trata de un espacio marcadamente vertical por dos motivos: por una parte, se produce la división mencionada entre dos mundos situados uno encima de otro, el divino sobre el terrenal, la bóveda perforada sobre el zócalo ciego, separados por una fina línea de imposta y una franja perimetral carente de tratamiento ornamental en su superficie; por otra parte, la entrada de luz tiene carácter cenital produciéndose, por tanto, desde lo alto y bajando en sentido descendente. Estos dos ámbitos quedan hilvanados por la entrada de luz desde arriba. El carácter vertical y estático viene determinado por el filtro establecido por la bóveda en la parte superior. Lo contrario ocurre en otros ámbitos del conjunto palaciego donde, conforme el espacio construido se va abriendo al paisaje de la ciudad, los cármenes y las montañas y relacionando con el exterior por medio de ventanas y celosías, las relaciones generadas se hacen más horizontales al predominar la presencia del paisaje exterior y relacionarse en mayor medida con el horizonte físico ${ }^{8}$.
[6]

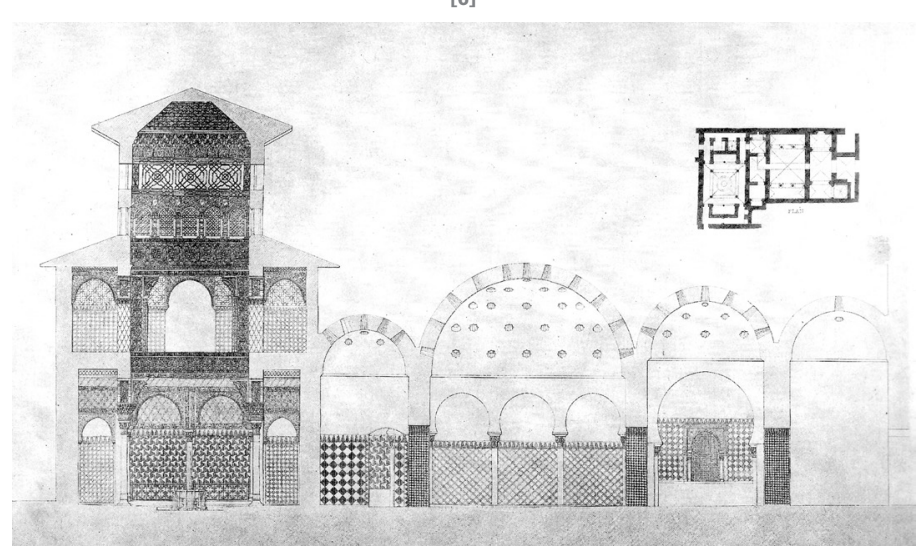

[7]

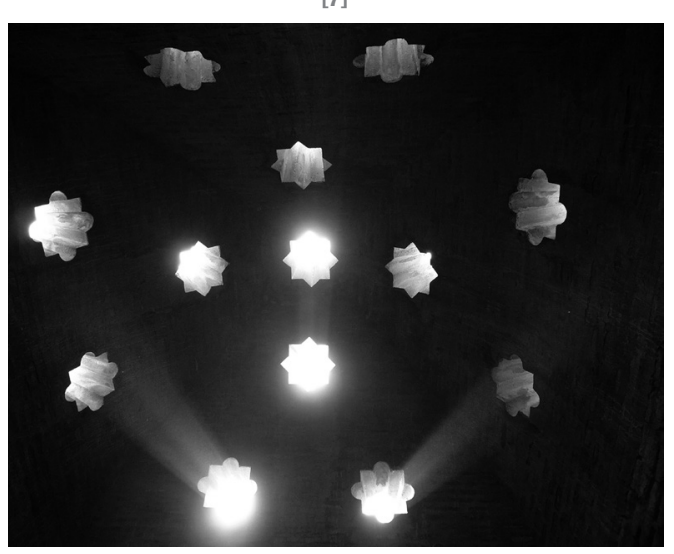


La plementería masiva de la bóveda central del hammam contiene un total de ochenta y cuatro perforaciones. Estas generan una suerte de recreación de la bóveda celeste cuya finalidad práctica era la de iluminar con luz dirigida y cortante la penumbra predominante y ventilar de forma adecuada el interior de los baños para evitar el exceso de vapor de agua de la sala, por lo que los huecos de estas bóvedas no estaban originariamente cerrados como sucede hoy día por cuestiones de preservación y mantenimiento. En el Baño Real del Palacio de Comares el ámbito celestial se perfora en las bóvedas superiores por medio de dos tipos distintos de huecos: una serie de estrellas de ocho puntas -dos cuadrados girados cuarenta y cinco grados uno respecto del otro, figura conocida como Rub el Hizb $b^{9}$ y otra serie de huecos en forma de gota o lágrima. La primera serie se divide además en dos tipos: estrellas con ocho puntas rectas -ángulos de noventa grados- y estrellas con cuatro de sus ocho puntas rematadas en semicírculo. Estas formas representan algunos de los elementos más relevantes de la bóveda celeste para la cultura Nazarí. Por una parte, las estrellas en la noche, tan presentes en el desierto que sirve de base a su tradicional trashumancia; por otra parte, las gotas de la lluvia, salvadora escasamente presente en esos mismos desiertos. Estas geometrías en las perforaciones de las bóvedas se producen de forma casi sistemática en los ejemplos existentes del período Nazarí. Por ejemplo, el hammam de Jaén, del siglo X, o el Bañuelo de Albaicín en Granada, del siglo XI, ambos anteriores y de dimensiones y acabados más humildes que el Baño Real de La Alhambra, articulan igualmente sus huecos superiores en dos formas geométricas básicas: estrellas de ocho puntas -una vez más, generadas por un giro a cuarenta y cinco grados de un cuadrado sobre otro, el Rub el Hizby octógonos regulares agrupados en tres bandas paralelas entre sí a lo largo de la directriz de la bóveda, en este caso de cañón, ocupando las formas estrelladas la línea central correspondiente a la clave del arco que hace de generatriz. [8]

Una cuestión que debe ser considerada es la de que ninguno de los huecos se sitúa a la altura de la mirada directa. Todas las perforaciones se ubican a una altura tal de la bóveda que hacen imposible cualquier relación visual directa entre interior y exterior, forzando la ausencia de vínculos entre ambos lados y acentuando todavía más la separación entre las escenas superior e inferior, la divina y la terrena, y, en consecuencia, la verticalidad del espacio. El filtro que forma la serie de perforaciones aleja al observador de todo contacto con el paisaje exterior, insistiendo así en el aislamiento de los baños. Todo ello no hace sino predisponer la percepción desde el vaciado de la masa continua de la tierra.

Si pensamos por un momento en cómo afectaría a la comprensión del espacio una hipotética presencia de una hilera de perforaciones a la altura de la mirada, podríamos confirmar que se produciría una seria contradicción en el resultado espacial y su significado: en primer lugar, la visión directa del exterior pasaría a ser un componente prioritario del espacio bajo el filtro estereotómico de la bóveda, lo que daría lugar, si no a una banalización del ámbito superior que escenifica la bóveda celeste, sí a una percepción del mismo de inferior importancia que llevaría a un relativo segundo plano; en segundo lugar, se produciria una ambivalencia entre el interés visual y conceptual de la bóveda estrellada y la introducción del horizonte en la escena interior, diluyendo de este modo el equilibrio vertical entre tierra y cielo y desviando parte de la atención al exterior; en tercer lugar, en el mencionado supuesto de que las perforaciones invadieran el área que escenifica el ámbito del hombre, se produciría un conflicto adicional con el zócalo al tener que fusionarse sendos elementos, lo que sin duda contribuiría a la confusión y, en consecuencia, a un más que posible fracaso del espacio que abandonaría su esquema vertical y la claridad en la distinción de los ámbitos terrenal y celestial, pasando a estar controlado por direcciones dispersas y carentes de intención. [9]

La tierra es en el Baño la materia con la que se construye el filtro de la bóveda. El área central o bayt al-wastani se levanta como una caverna cuya única relación con el mundo exterior se produce en la parte superior. La luz entrante marca la mencionada verticalidad y descubre una arquitectura que nace desde el subsuelo, desde abajo, partiendo del peso del plano horizontal al que el hombre está atado. Existe en el conjunto de la Alhambra un constante proceso de ida y vuelta entre las soluciones estereotómica y tectónica, que llega a alcanzar altos grados de complejidad y riqueza en las relaciones espaciales entre los distintos ámbitos del conjunto. El conjunto presenta una arquitectura físicamente estática que es sin embargo percibida de forma dinámica en función del movimiento del observador y de la luz. Por medio de filtros se construye un límite entre la arquitectura y la naturaleza creado para generar emoción en el observador. Este es activo en su percepción tanto de la naturaleza arquitectonizada de los jardines como de la arquitectura naturalizada del palacio, y admite las secuencias que le son ofrecidas a lo largo del conjunto nazarí, resueltas por medio de estrategias arquitectónicas donde la percepción se va construyendo mediante la superposición de salas, huecos y ornamentación a modo de diafragmas espaciales.
9 El Rub el Hizb (rub' al-hizb) es un símbolo islámico representado por dos cuadrados superpuestos girados 45 grados uno respecto de otro. En árabe clásico el término Rub significa "una cuarta parte" mientras que Hizb se refiere a un grupo. Dicho símbolo fue empleado inicialmente en el Corán, el cual se dividia en sesenta Hizb -sesenta grupos de extensión muy similar-. El propósito principal de dicha división era el de facilitar el recital del texto sagrado, pues el símbolo en cuestión se ubicaba al final de cada capítulo en la caligrafia árabe. De igual forma, la estrella de ocho puntas se utilizaba como símbolo en la cultura de los Tartesos, ubicada en Andalucía, región que fue posteriormente ocupada durante ocho siglos. Esta circunstancia puede explicar de forma parcial el origen del símbolo Rub el Hizb. Véase BURCKHARDT, Titus, La Civilización Hispano-Árabe, Madrid: Alianza Editorial, Colección Alianza Universidad, 1977.

10 Resultaría muy atractiva una comparación entre los limites construidos encontrados en el conjunto de la Alhambra y en la Villa Imperial Katsura, en Kioto, del siglo XVII (1615-1662). En ambos ejemplos el espacio se percibe en movimiento, en el recorrido entre pabellones. Dicho recorrido plantea, sin embargo, momentos de contemplación estáticos: marcos que enmarcan, juegos de continuidad y simetría, fondos solapados que configuran escenas compuestas para la quietud, que solo pueden entenderse enmarcadas en un recorrido global de carácter dinámico. La villa imperial y el palacio granadino están concebidos para la contemplación estructurada en secuencias planas que aspiran a formar composiciones armónicas entre los distintos elementos del paisaje arquitectónico y del natural. Si bien los cerramientos están constituidos de forma muy simple y eficaz, también es cierto que se incorpora el parámetro movimiento en la construcción de esos bordes. Véase SEDLMAYR, Hans, La luz en sus manifestaciones artísticas, (1960), Colección La luz y su anverso, número 02, Madrid: Editorial Lampreave, 2011. Traducción de Stefano Giuliani. 
Las perforaciones en el conjunto de la Alhambra requieren de la intervención de agentes que condicionan su percepción estática o dinámica: el movimiento de la luz, el movimiento del observador y el paso del tiempo. Si imaginamos la bóveda central del baño Real del Palacio de Comares bajo el influjo de la luz y su evolución a lo largo del día y de las estaciones, ¿nos atreveríamos a pensar que ese espacio construido es estático o pesado? Con probabilidad pensaríamos que la activación por medio de la luz en el tiempo alivia el peso de la construcción y modifica constantemente la arquitectura en un devenir que no es en modo alguno estático. Sin embargo, estas apreciaciones ocurren por contraste. El movimiento en la direccionalidad de la luz calada determina el estatismo de la propia bóveda así como el peso de esta, que queda en evidencia por los haces de luz que sin peso la atraviesan. No obstante, las apreciaciones sobre los espacios de la Alhambra encierran cuestiones que no permiten lecturas directas, sino que obligan a proceder con visiones complementarias sobre los recorridos y los espacios del conjunto. $\mathrm{Si}$ reflexionamos sobre el movimiento generado tras los filtros de la Alhambra, veremos que los bordes se construyen como fundamentalmente estáticos y que quedan enlazados y articulados por medio de movimientos y direcciones predeterminados en forma de vistas, recorridos y perspectivas. Los parámetros de quietud y movimiento en la construcción de los filtros que componen los bordes exteriores de la Alhambra permiten enriquecer los resultados espaciales y pensar en términos de complejidad lumínica o espacial. En las salas de los palacios de la Alhambra se plantean cerramientos de gran riqueza que no incorporan el movimiento stricto sensu en sí mismas. En este caso son los movimientos del observador y de la luz los que irán determinando los efectos de filtro generados en sus límites ${ }^{10}$. Esto multiplica las opciones de percepción e implica al observador en la construcción misma del espacio. Comprobamos por tanto que los filtros de sus bóvedas hacen uso de una notable ambigüedad que llega a modificar por completo la percepción del espacio que construyen. [10]

Podríamos asumir que el baño del Palacio de Comares se experimenta desde una doble estrategia: la del estatismo del baño como espacio consolidado y no cambiante, relacionado por su masa y su condición original de la tierra de la que surge y sobre la que asienta, que se infunde de vida al ser intervenida por la luz escenográfica de su filtro superior; y la del movimiento establecido del recorrido del visitante en el marco permanente de la masa continua en la que se perforan los huecos que enlazan con el exterior. La propia arquitectura, tan implacable en su trazado que no concibe los recorridos no controlados, define con precisión la secuencia del movimiento trazado por el visitante. El baño Real podría describirse conceptualmente como una cueva excavada en la tierra que mira al cielo con 84 ojos perforados en su bóveda superior que iluminan y observan a quien pasa bajo su manto. Es tal vez la ilusión de una tierra perfecta bajo un cielo perfecto, el plano espiritual inalcanzable que se convierte en el gran protagonista del baño, condicionando con su mirada vertical todo lo que bajo él acontece. El espacio dirige su mirada siempre hacia el mismo sitio: un cielo casi oculto al otro lado del filtro de la cubierta, cuya materia densa e inaccesible establece un continuo diálogo entre la tierra y la luz, logrando un equilibrio que en los baños se construye en permanente flotación. La constante relación que se establece entre el visitante y el plano del cielo determina el carácter de la experiencia espacial, tensionando su posición entre los dos planos, suelo y bóveda, tierra y cielo, y configurando en el medio el ámbito del paraíso. El espacio construido parece acomodado en la tierra para mirar y ser mirado desde el cielo.
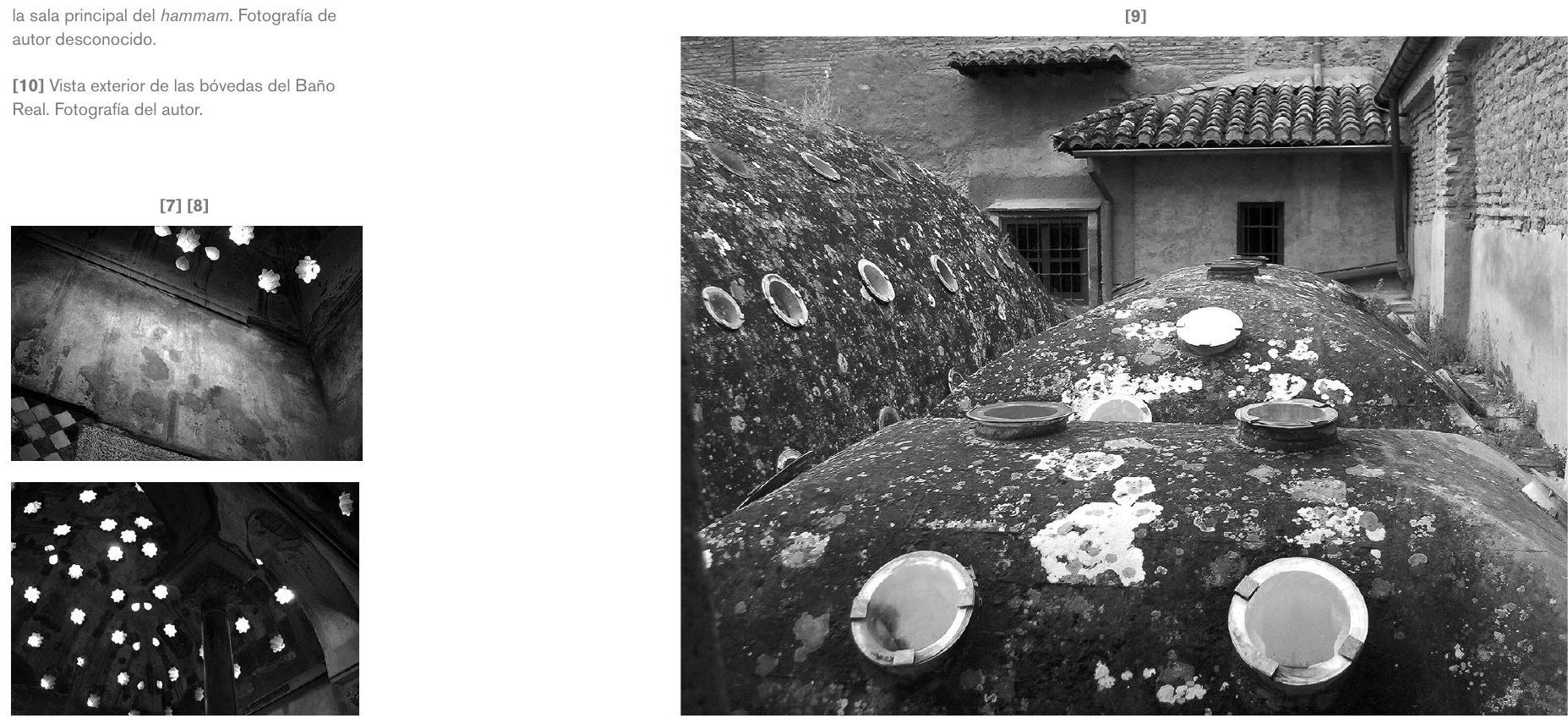